\title{
Design and Analysis of Closed Loop Control of Multilevel SVPWM Inverter Fed PMSM Drive
}

\author{
Lavanya Komma, Alice Mary Karlapudy, Saraswathi G
}

\begin{abstract}
Permanent magnet synchronous machines have been universally used over induction machines in variable speed drives. For present trends and future developments, power electronics technology gives the extensive research of multilevel inverters that brings high safety voltages with low harmonic content in comparison with two-level inverter strategies. Multi level inverters implementation can be done by raising the number of power semi conductor controlled switching devices per phase to increase the number of inverter output voltage levels. By increasing the levels, power controlled switching devices and other components are increased, which makes the inverter complex and overpriced. From the above aspects, three-phase three-level inverter strategy is used for high performance and high voltage A.C drives. Multilevel inverter using a space vector pulse width modulation (SVPWM) strategy gives great advantages in high performance A.C drive applications. Various types of control strategies have been recommended for voltage source inverter fed A.C drives. In the proposed work, a PI controller is designed for the outer loop and non-linear controller using a state feedback linearization technique is designed for the inner loop. The closed loop control system for three-level inverter fed Permanent magnet synchronous motor drive employing SVPWM is extensively simulated using MATLAB.
\end{abstract}

Key words: Feedback linearization technique (FLT), Permanent modulation (SVPWM).

\section{INTRODUCTION}

$\mathrm{I}_{\mathrm{n}}$ industrial drive applications, PWM inverters are growing popularity in recent years. The main reasons are improvement of the harmonic quality and easy large voltage sharing between the controlled switches [1]. The basic two-level inverter is simple in calculation and switching selection, but it becomes complicated in HV \& HP applications due to more switching losses and a limited range of D.C link voltage. Reduction of harmonic content in a basic two-level inverter topology is obtained by boosting the switching frequency. In the case of high voltage (HV) \& high power (HP) applications, the frequency of power semi conductor controlled switching device is limited up to $1 \mathrm{KHz}$.

Revised Manuscript Received on August 20, 2019.

* Correspondence Author

Lavanya Komma *, EEE, ANITS, Visakhapatnam, A.P, India lavanya.eee@anits.edu.in

Alice Mary Karlapudy, EEE, GEC, Krishna district, India.

Saraswathi G, EEE, JNTUV, Vijayanagaram, India. Magnet Synchronous motor (PMSM), Space vector pulse width

So the harmonic content reduction in a basic two-level inverter seems to be more difficult in HP applications. Hence, recently multilevel inverter topology gives great attention in HP \& HV industrial applications because of their ability to synthesize stepped waveform with better harmonic content reduction and also high D.C-link voltage level. They reduce the voltage stress across switches which cause less EMI problems [2].

By increasing the inverter voltage levels without providing higher ratings on individual power switching devices can raise the power rating which leads to a harmonic reduction content in the output inverter waveforms.

The neutral-point clamped 3-phase 3-level inverter topologies recently gave vast reputation for such applications. Researchers organized several studies on multilevel converters. Among various PWM techniques, Space vector PWM strategy is the most attractive one. It uses the control variable given by a control system and describes active switching vectors in 2-axis space [3].3-level SVPWM inverter provides the additional advantage of superior harmonic spectrum and easy digital implementation. An A.C drive system requires advanced control topologies for controlling current, voltage and frequency. They have more advantages over dc drives.

PMSM drives are extensively used in pumps, machine tools, industrial applications, robotics, agricultural, and ventilators due to various features over other A.C machine drives such as easy controllability, good dynamic performance, lesser volume, light weight, high efficiency, and wide speed range applications [4]. There is no field winding in PMSM and the field winding is replaced by permanent magnets in to the rotor. PMSM attains improved efficiency and power factor due to elimination of dc supply, field coil and slip rings decrease the machine losses and complications. PMSM drives directly from the main supply, the torque will automatically arise related to the load will leads to the fluctuation of load torque angle until the steady state operation is reached [5]. Design of control system for voltage source inverter fed A.C drives universally used the classical transfer function method. Proportional and integral (PI) controllers are fabricated for individual control loops. 


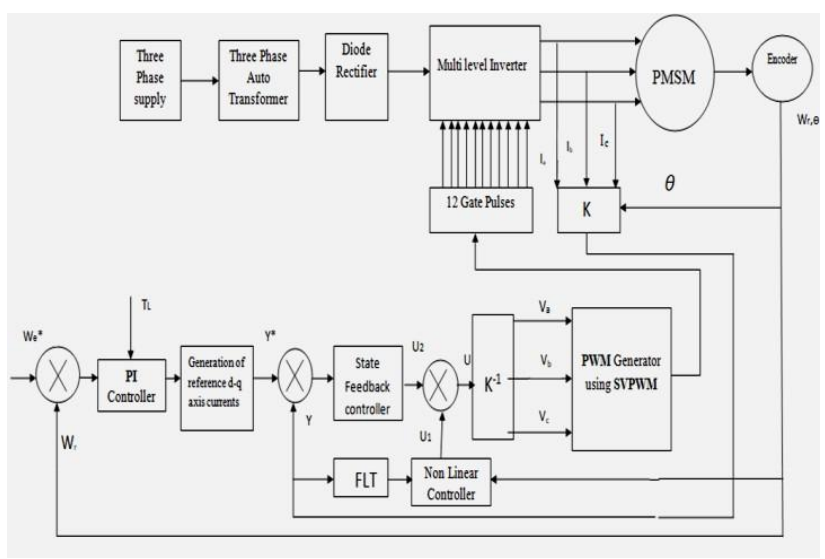

Fig.1. Schematic layout of the planned control approach

The proposed control strategy is designed by employing conventional two-loop structure for 3-phase 3-level inverter fed AC motor drive by using SVPWM scheme. In this work, a current controller is described as the inner loop and the PI controller is described as the outer loop. D-q axis reference currents are generated by using the output response of the PI controller for a desired torque angle and internal angle. Actual d-q axis reference currents are sensed from stator of inverter fed PMSM by using sensors. The Transient response of a PI (proportional and integral) controller is slow, and it is upgraded by using state feedback control law. The output of the control strategy is applied to the PWM generator; it generates 12 firing pulses using SVPWM technique.

The proposed scheme is described as follows: the first implementation of a 3-level SVPWM inverter scheme in section II. Then the mathematical modeling of 3-level voltage source inverter fed PMSM is formulated in section III. Control system design is presented in section IV. Finally, simulation coding results and discussions in section $\mathrm{V}$ and conclusions in section IV are presented.

\section{ANALYSIS OF 3- LEVEL SVPWM INVERTERS}

Design steps for generating firing pulses:

(1) To find number of switching states.

(2) To find number of active and zero voltage vectors.

(3) To select the particular sector.

(4) To identify region in a particular sector

(5) To calculate sub-sector angle.

(6) To calculate active vector switching time periods

(7) To determine switching segments.

(8) To arrange on times for upper switches in each arm

(9) To map on time periods to other sectors

(10) To generate 12 firing pulses

\section{A. Switching States}

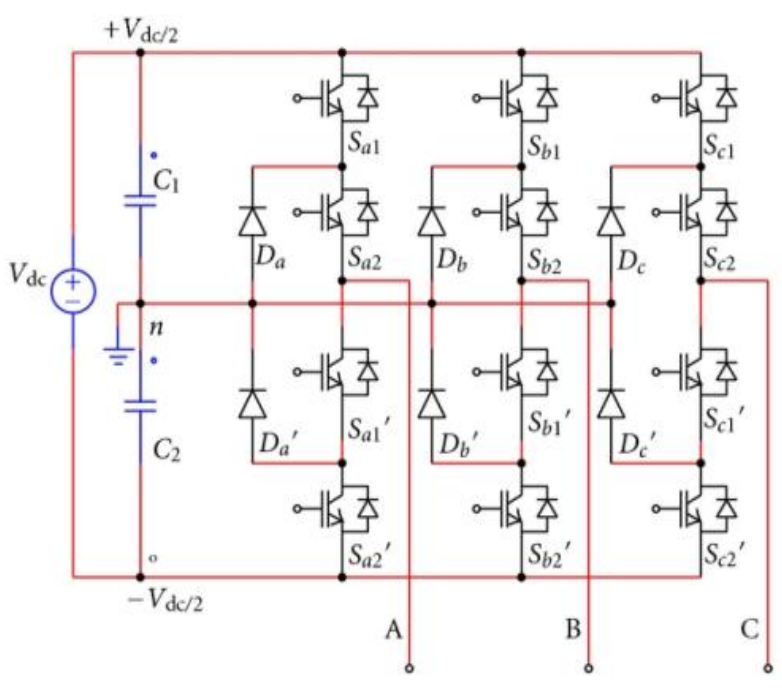

Fig.2. Structure of diode clamped 3-level inverter

An M-level NPC inverter expressed by (M-1) D.C bus capacitors, $2 *(\mathrm{M}-1)$ power semiconductor devices per arm, (M-1)* (M-2) clamping diodes per arm, $\mathbf{M}^{3}$ switching states. $\mathrm{M}$ refers to the number of levels. 3-phase-3 level inverter has 27 switching states (SW). Among these states 24 are active and remaining 3 are zero states. Each arm consists of four power controlled switching devices. Each arm switching state is indicated by $\mathrm{SW}_{\mathrm{A}}, \mathrm{SW}_{\mathrm{B}} \& \mathrm{SW}_{\mathrm{C}}$. Three possible cases to synthesize the 3-level inverter output voltages are

(1)If an output voltage level of each arm is equal to, turn on the upper two switches. It is represented as a state 1.

(2)If an output voltage level of each arm is equal to 0 , turn on the middle two switches. It is represented as a state $\mathbf{0 .}$

(3) If an output voltage level of each arm is equal to $\frac{i c}{\text { : }}$, turn on the lower two switches. It is represented as a state $\mathbf{- 1}$.

\section{B. Voltage Vectors}

3-phase 3-level inverter consists of 27 voltage vectors demonstrated in table I. These vectors are split into 4 categories of vectors, they are

(1) 3 zero voltage vectors. These are redundant vectors.

(2) 6 positive and 6 negative voltage vectors forms a small inner hexagon. These are redundant vectors.

(3) 6 medium vectors bisecting the sides of the outer hexagon.

(4) 6 large vectors forms the large outer hexagon 
Table-I: Device switching states and its voltage vectors

\begin{tabular}{|c|c|c|c|c|}
\hline \multicolumn{2}{|c|}{ Space vector } & \multicolumn{2}{|c|}{ DEVICE Switching states } & $\begin{array}{c}\text { Vector } \\
\text { magnitude }\end{array}$ \\
\hline \multicolumn{2}{|c|}{$\mathrm{V}_{\mathrm{o}}$} & \multicolumn{2}{|c|}{$(111),(-1-1-1),(000)$} & ZERO VECTOR (0) \\
\hline \multirow[t]{3}{*}{$\mathrm{V}_{1}$} & & $\begin{array}{l}\text { POSITIVE } \\
\text { GROUP }\end{array}$ & $\begin{array}{c}\text { NEGATIVE } \\
\text { GROUP }\end{array}$ & \multirow{13}{*}{$\begin{array}{c}\text { SMALL VECTOR } \\
\left(\frac{V_{\text {de }}}{3}\right)\end{array}$} \\
\hline & $\mathrm{V}_{\mathrm{lP}}$ & (100) & & \\
\hline & $\mathrm{V}_{1 \mathrm{~N}}$ & & $(0-1-1)$ & \\
\hline \multirow{2}{*}{$\mathrm{V}_{2}$} & $\mathrm{~V}_{2 \mathrm{P}}$ & (110) & & \\
\hline & $\mathrm{V}_{2 \mathrm{~N}}$ & & $(00-1)$ & \\
\hline \multirow{2}{*}{$\mathrm{V}_{3}$} & $\mathrm{~V}_{3 \mathrm{P}}$ & (010) & & \\
\hline & $\mathrm{V}_{3 \mathrm{~N}}$ & & $(-10-1)$ & \\
\hline \multirow{2}{*}{$\mathrm{V}_{4}$} & $\mathrm{~V}_{4 \mathrm{P}}$ & (011) & & \\
\hline & $\mathrm{V}_{4 \mathrm{~N}}$ & & $(-100)$ & \\
\hline \multirow{2}{*}{$\mathrm{V}_{5}$} & $\mathrm{~V}_{5 \mathrm{P}}$ & (001) & & \\
\hline & $\mathrm{V}_{5 \mathrm{~N}}$ & & $(-1-10)$ & \\
\hline \multirow{2}{*}{$\mathrm{V}_{6}$} & $\mathrm{~V}_{6 \mathrm{P}}$ & (101) & & \\
\hline & $\mathrm{V}_{6 \mathrm{~N}}$ & & $(0-10)$ & \\
\hline \multicolumn{2}{|c|}{$\mathrm{V}_{7}$} & \multicolumn{2}{|c|}{$(10-1)$} & \multirow{6}{*}{$\begin{array}{l}\text { MEDIUM VECTOR } \\
\qquad\left(\mathrm{V}_{\mathrm{DC}} / \sqrt{3}\right)\end{array}$} \\
\hline & $\mathrm{V}_{8}$ & \multicolumn{2}{|c|}{$(01-1)$} & \\
\hline \multicolumn{2}{|r|}{$\mathrm{V}_{9}$} & \multicolumn{2}{|c|}{$(-110)$} & \\
\hline \multicolumn{2}{|c|}{$\mathrm{V}_{10}$} & \multicolumn{2}{|c|}{$(-101)$} & \\
\hline & $\overline{V_{11}}$ & \multicolumn{2}{|c|}{$(0-11)$} & \\
\hline & $\mathrm{V}_{12}$ & \multicolumn{2}{|c|}{$(1-10)$} & \\
\hline & $V_{13}$ & \multicolumn{2}{|c|}{$(1-1-1)$} & \multirow{6}{*}{$\begin{array}{c}\text { LARGE VECTOR } \\
\left(\frac{2}{3}\right) \mathrm{V}_{\mathrm{DC}}\end{array}$} \\
\hline & $V_{14}$ & \multicolumn{2}{|c|}{$(11-1)$} & \\
\hline & $\overline{V_{15}}$ & \multicolumn{2}{|c|}{$(-11-1)$} & \\
\hline & $\mathrm{V}_{16}$ & \multicolumn{2}{|c|}{$(-111)$} & \\
\hline & $\overline{V_{17}}$ & \multicolumn{2}{|c|}{$(-1-11)$} & \\
\hline & $V_{18}$ & \multicolumn{2}{|c|}{$(1-11)$} & \\
\hline
\end{tabular}

\section{Selection of Sector and Region}

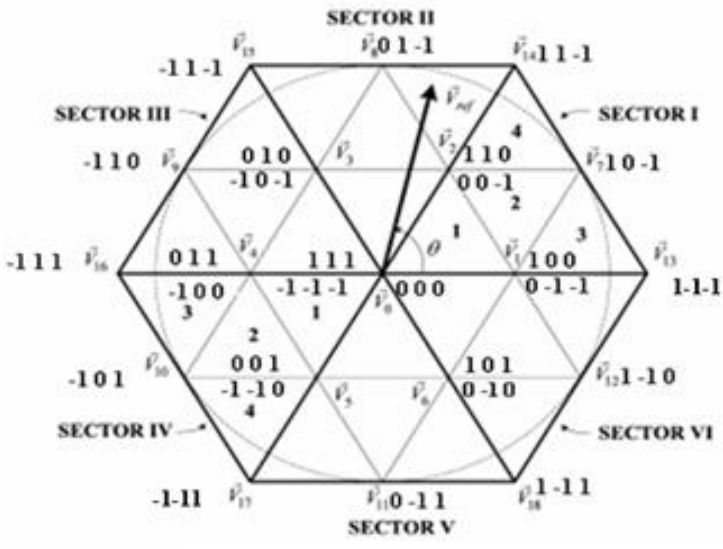

Fig.3. SV plane of NPC 3-level inverter

By using a quasi-circular locus method, SV diagram is drawn as shown in fig.3. Space vector axis can be sectioned into six major triangular sectors. Each sector can be identified by using a space vector angle. Each sector is $60^{\circ}$ and it is again sub-divided into 4 minor triangular regions.
$V_{\alpha}=\frac{2}{3} V_{a n}-\frac{V_{b n}}{3}-\frac{V_{c n}}{3}$

$V_{\beta}=0.577\left(V_{b n}-V_{c n}\right)$

Reference voltage $\left(\mathrm{V}_{\text {ref }}\right)=\mathrm{V}_{\alpha}+\mathrm{j} \mathrm{V}_{\beta}$

Space vector angle $(\theta)=\tan ^{-1} \frac{V_{B}}{V_{\text {II }}}$

Space vector angle is calculated by which sector is determined in which reference vector $\left(\mathrm{V}_{\text {ref }}\right)$ is located. Space vector and sub-sector angle is determined as following the table II.

Table-II: Angle selection

\begin{tabular}{|c|c|c|}
\hline SECTOR & $\begin{array}{c}\text { SPACE VECTOR } \\
\text { ANGLE( }(\boldsymbol{)})\end{array}$ & $\begin{array}{c}\text { SUB-SECTOR } \\
\text { ANGLE(A) }\end{array}$ \\
\hline 1 & $0^{0} \leq \Theta<60^{0}$ & $\mathrm{~A}=\Theta$ \\
\hline 2 & $60^{0} \leq \Theta<120^{\circ}$ & $\mathrm{A}=\Theta-\Pi / 3$ \\
\hline 3 & $120^{0} \leq \Theta<180^{\circ}$ & $\mathrm{A}=\Theta-2 \Pi / 3$ \\
\hline 4 & $180^{0} \leq \Theta<240^{0}$ & $\mathrm{~A}=\Theta-\Pi$ \\
\hline 5 & $240^{\circ} \Theta<300^{\circ}$ & $\mathrm{A}=\Theta-4 \Pi / 3$ \\
\hline 6 & $300^{0} \leq \Theta<360^{\circ}$ & $\mathrm{A}=\Theta-5 \Pi / 3$ \\
\hline
\end{tabular}

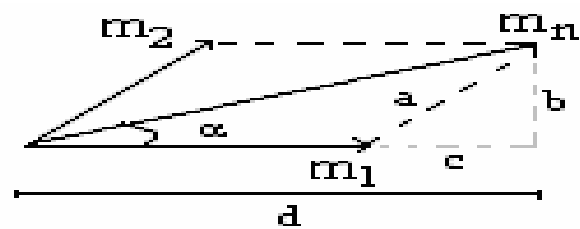

Fig.4.Region identification

$\mathrm{V}_{\text {ref }}$ is the voltage reference vector and $\mathrm{V}_{\mathrm{dc}} / \sqrt{3}$ is the magnitude of medium voltage vector. $m$ assigned to modulation index and defined as the ratio of reference voltage vector to medium voltage vector. Table III demonstrates conditions for finding of a region in each sector. $\mathrm{m}_{1}=\mathrm{m}_{\mathrm{x}}$ and $\mathrm{m}_{2}=\mathrm{m}_{\mathrm{y}}$.

$$
\begin{aligned}
& m_{1}=\frac{m}{\sqrt{3}}(\sqrt{3} \cos \alpha-\sin \alpha) \\
& m_{2}=m\left(\frac{2}{\sqrt{3}} \sin \alpha\right)
\end{aligned}
$$

Table-III: Identification of a region

\begin{tabular}{|c|c|}
\hline REGION NUMBER & SATISFIED CONDITIONS \\
\hline 1 & $\begin{array}{c}\mathrm{M}_{\mathrm{Y}}<0.5 \& \mathrm{M}_{\mathrm{X}}<0.5 \&\left(\mathrm{M}_{\mathrm{X}}+\right. \\
\left.\mathrm{M}_{\mathrm{Y}}\right)<0.5\end{array}$ \\
\hline 2 & $\begin{array}{c}\mathrm{M}_{\mathrm{Y}}<0.5 \& \mathrm{M}_{\mathrm{X}}<0.5 \& \\
\left(\mathrm{M}_{\mathrm{X}}+\mathrm{M}_{\mathrm{Y}}\right)>0.5\end{array}$ \\
\hline 3 & $\mathrm{M}_{\mathrm{X}}>0.5$ \\
\hline 4 & $\mathrm{M}_{\mathrm{Y}}>0.5$ \\
\hline
\end{tabular}

\section{Calculation of Switching Device Time Periods}

The SV diagram can be used for computing the switching time periods for every sector and its region. Consider a $V_{\text {ref }}$ is placed in a second region of the $1^{\text {st }}$ sector, then the 3 nearest voltage vectors are $\mathrm{V}_{1}, \mathrm{~V}_{7}$ and $\mathrm{V}_{2} . \mathrm{T}_{\mathrm{a}}, \mathrm{T}_{\mathrm{b}} \& \mathrm{~T}_{\mathrm{c}}$ are controlled switching time periods. According as the three nearest voltage vector approach method, time periods are calculated.

$$
\begin{aligned}
& \mathrm{V}_{\text {ref }} * \mathrm{~T}_{\mathrm{s}}=\left(\mathrm{V}_{1} \mathrm{~T}_{\mathrm{a}}\right)+\left(\mathrm{V}_{7} \mathrm{~T}_{\mathrm{b}}\right)+\left(\mathrm{V}_{2} \mathrm{~T}_{\mathrm{c}}\right) \\
& \mathrm{T}_{\mathrm{s}}=\left(\mathrm{T}_{\mathrm{a}}+\mathrm{T}_{\mathrm{b}}+\mathrm{T}_{\mathrm{c}}\right) \\
& V_{1}=\left(\frac{V_{d c}}{3}\right) e^{j 0}=\frac{V_{d c}}{3}
\end{aligned}
$$




$$
\begin{aligned}
& V_{2}=\left(\frac{V_{d c}}{3}\right) e^{j \frac{\pi}{3}}=\frac{V_{d c}}{3}\left(\cos \frac{\pi}{3}+j \sin \frac{\pi}{3}\right) \\
& V_{7}=\left(\frac{V_{d c}}{\sqrt{3}}\right) e^{j \frac{\pi}{6}}=\frac{V_{d c}}{\sqrt{3}}\left(\cos \frac{\pi}{6}+j \sin \frac{\pi}{6}\right) \\
& V_{r e f}=V_{r e f} e^{j \theta}=V_{r e f}(\cos \theta+j \sin \theta)
\end{aligned}
$$

On substituting Eq. (9), (10), (11), and (12) in Eq. (7) and Write the real parts and imaginary parts equations separately. Then,

$$
\begin{aligned}
& \left(V_{\text {ref }} \cos \theta\right) T_{s}=V_{d c}\left(\frac{T_{a}}{3}+\frac{T_{b}}{2}+\frac{T_{c}}{6}\right) \\
& \left(V_{r e f} \sin \theta\right) T_{s}=V_{d c}\left(\frac{T_{b}}{2}+\frac{T_{c}}{2 \sqrt{3}}\right) \\
& (\sqrt{3} \cos \theta) T_{s}=\left(T_{a}+\frac{3 T_{b}}{2}+\frac{T_{c}}{2}\right) \\
& (\sqrt{3} \cos \theta) T_{s}=\left(\frac{3 T_{b}}{2}+\frac{\sqrt{3} T_{c}}{2}\right)
\end{aligned}
$$

By solving Eq. (15) \& (16) with Eq. (8), switching device time period expressions can be derived.

$$
\begin{aligned}
& T_{a}=T_{s}-T_{s} 2 m \sin \theta \\
& T_{b}=T_{s} 2 m \sin \left(\frac{\pi}{3}+\theta\right)-T_{s} \\
& T_{c}=T_{s}-T_{s} 2 m \sin \left(\frac{\pi}{3}-\theta\right)
\end{aligned}
$$

These are switching time period expressions for the region 2 in sector1. Similarly switching times for the remaining sectors and its regions can be determined $[6,7]$.

\section{E. Switching Sequence}

Table IV gives the information related to the switching sequences for the upper two devices in each arm for sector 1 in region 1 [8].For an example consider the switching state 110 for the upper two devices in each phase. In this case $S_{\mathrm{a} 1}$, $\mathrm{S}_{\mathrm{a} 2}, \mathrm{~S}_{\mathrm{b} 1}, \mathrm{~S}_{\mathrm{b} 2}, \mathrm{~S}_{\mathrm{c} 2}$ are in on and $\mathrm{S}_{\mathrm{c} 1}$ is in off state and corresponding duration is $T_{c} / 4$. If the $V_{\text {ref }}$ is detected in the first region in the first sector, switching pattern of the firing commands would be $110,100,000,00-1,0-1-1,0-1-1,00-1,000,100,110$ with, the durations $\frac{T_{c}}{4}, \frac{T_{a}}{4}, \frac{T_{b}}{2}, \frac{T_{c}}{4}, \frac{T_{a}}{4}, \frac{T_{a}}{4}, \frac{T_{c}}{4}, \frac{T_{b}}{2}, \frac{T_{c}}{4}, \frac{T_{a}}{4} \& \frac{T_{c}}{4}$. Switches $\mathrm{S}_{\mathrm{a} 1}$, $\mathrm{S}_{\mathrm{b} 1} \& \mathrm{~S}_{\mathrm{c} 1}$ are complementary switches to $\mathrm{S}_{\mathrm{a} 1}, \mathrm{~S}_{\mathrm{b} 1}$ \& $\mathrm{S}_{\mathrm{c} 1}$. Similarly remaining switches $\mathrm{S}_{\mathrm{a} 2}, \mathrm{~S}_{\mathrm{b} 2} \quad \& \quad \mathrm{~S}_{\mathrm{c} 2}$ are complementary switches to $\mathrm{S}_{\mathrm{a} 2}, \mathrm{~S}_{\mathrm{b} 2}$ \& \& $\mathrm{S}_{\mathrm{c} 2}$ ' [9]. All the lower power controlled switches in each phase generates opposite on and off time periods for each state. Table $\mathrm{V}$ gives the on-time period duration of all switches in one sampling period.

\section{MATHEMATICAL MODELING OF A SVPWM 3-LEVEL INVERTER FED PMSM}

The mathematical analysis of a wound type rotor synchronous motor can be treated for reference in order to develop mathematical design of PMSM drive. The dynamic equations of a 3-level inverter PMSM can be formulated by using differential equations related to voltages, speed, currents, fluxes and torque. The model of 3-level SV pulse width modulated inverter fed PMSM drive has been worked out on d-q rotor axis reference frame. The voltage equations of PMSM drive using d-q rotor axis reference frame are.

$V_{q s}^{r}=r_{q} i_{q s}^{r}+l_{q s} \rho i_{q s}^{r}+l_{a q} \rho i_{q r}^{r}+\omega_{r} l_{a d} i_{d r}^{r}+\omega_{r} l_{d s} i_{d s}^{r}+\omega_{r} \psi(20)$

\begin{tabular}{|c|c|}
\hline SWITCHES & ON TIME PERIODS \\
\hline $\mathrm{S}_{\mathrm{A} 1}$ & $\frac{T_{c}}{2}+\frac{T_{a}}{2}$ \\
\hline $\mathrm{S}_{\mathrm{A} 2}$ & $\mathrm{~T}_{\mathrm{S}}$ \\
\hline $\mathrm{S}_{\mathrm{A} 1}$ & $T_{s}-\frac{T_{c}}{2}-\frac{T_{a}}{2}$ \\
\hline $\mathrm{S}_{\mathrm{A} 2}$ & 0 \\
\hline $\mathrm{S}_{\mathrm{B} 1}$ & $\frac{T_{c}}{2}$ \\
\hline $\mathrm{S}_{\mathrm{B} 2}$ & $T_{s}-\frac{T_{a}}{2}$ \\
\hline $\mathrm{S}_{\mathrm{B} 1}$ & $T_{s}-\frac{T_{c}}{2}$ \\
\hline $\mathrm{S}_{\mathrm{B} 2}$ & $\frac{T_{a}}{2}$ \\
\hline $\mathrm{S}_{\mathrm{C} 1}$ & 0 \\
\hline $\mathrm{S}_{\mathrm{C} 2}$ & $T_{s}-\frac{T_{a}}{2}-\frac{T_{c}}{2}$ \\
\hline $\mathrm{S}_{\mathrm{C} 1}$ & $\mathrm{~T}_{\mathrm{S}}$ \\
\hline $\mathrm{S}_{\mathrm{C} 2}$ & $\frac{T_{c}}{2}+\frac{T_{a}}{2}$ \\
\hline
\end{tabular}

$V_{q s}^{s}=r_{q} i_{q s}^{r}+l_{q s} \rho i_{q s}^{\gamma}+l_{a q} \rho i_{q r}^{r}+\omega_{r} l_{a d} i_{d r}^{r}+\omega_{r} l_{d s} i_{d s}^{r}$

$V_{q s}^{\prime}=r_{q} i_{q s}^{r}+\omega_{y} l_{d s} i_{d s}^{r}$

$V_{d s}^{r}=r_{d} i_{d s}^{r}-\omega_{r} l_{q s} i_{q s}^{r}$
Table-IV: The switching sequence for the upper two devices

\begin{tabular}{|c|c|c|c|c|c|c|c|c|}
\hline STATE & $\begin{array}{c}\mathbf{V}_{\mathbf{C}} \\
\mathbf{R}\end{array}$ & $\mathbf{T I M E}$ & $\mathbf{S}_{\mathbf{A} 1}$ & $\mathbf{S}_{\mathbf{A} \mathbf{2}}$ & $\mathbf{S}_{\mathbf{B} \mathbf{1}}$ & $\mathbf{S}_{\mathbf{B} \mathbf{2}}$ & $\mathbf{S}_{\mathbf{C} \mathbf{1}}$ & $\mathbf{S}_{\mathbf{C} 2}$ \\
\hline 110 & $\mathrm{~V}_{2}$ & $\mathrm{~T}_{\mathrm{C}} / 4$ & 1 & 1 & 1 & 1 & 0 & 1 \\
\hline 100 & $\mathrm{~V}_{1}$ & $\mathrm{~T}_{\mathrm{A}} / 4$ & 1 & 1 & 0 & 0 & 0 & 1 \\
\hline 000 & $\mathrm{~V}_{0}$ & $\mathrm{~T}_{\mathrm{B}} / 2$ & 0 & 1 & 0 & 0 & 0 & 1 \\
\hline $00-1$ & $\mathrm{~V}_{2}$ & $\mathrm{~T}_{\mathrm{C}} / 4$ & 0 & 1 & 0 & 0 & 0 & 0 \\
\hline $0-1-1$ & $\mathrm{~V}_{1}$ & $\mathrm{~T}_{\mathrm{A}} / 4$ & 0 & 1 & 0 & 0 & 1 & 0 \\
\hline $0-1-1$ & $\mathrm{~V}_{1}$ & $\mathrm{~T}_{\mathrm{A}} / 4$ & 0 & 1 & 0 & 0 & 1 & 0 \\
\hline $00-1$ & $\mathrm{~V}_{2}$ & $\mathrm{~T}_{\mathrm{C}} / 4$ & 0 & 1 & 0 & 0 & 0 & 0 \\
\hline 000 & $\mathrm{~V}_{0}$ & $\mathrm{~T}_{\mathrm{B}} / 2$ & 0 & 1 & 0 & 0 & 0 & 1 \\
\hline 100 & $\mathrm{~V}_{1}$ & $\mathrm{~T}_{\mathrm{A}} / 4$ & 1 & 1 & 0 & 0 & 0 & 1 \\
\hline 110 & $\mathrm{~V}_{2}$ & $\mathrm{~T}_{\mathrm{C}} / 4$ & 1 & 1 & 1 & 1 & 0 & 1 \\
\hline
\end{tabular}

Table-V: On time periods

The developed electrical torque equation is

$T_{e}=\frac{a}{2} \frac{p}{2}\left[\lambda_{d s} i_{q s}^{r}-\lambda_{q s} i_{d s}^{r}\right]$

D \& $\mathrm{q}$ axis Flux linkages are

$\lambda_{d s}=l_{d s} i_{d s}^{r}+\psi$

$\lambda_{q s}=l_{q s} i_{q s}^{r}$

Substituting Eq. (25), (26) in Eq. (24), developed electrical torque is

$T_{e}=\frac{a}{2} \frac{p}{2}\left[\left(l_{a d}-l_{a q}\right) i_{d s}^{r} i_{q s}^{r}+l_{a d} i_{q s}^{r} i_{d r}^{r}-l_{a q} i_{d s}^{r} i_{q r}^{r}-\psi i_{q s}^{r}\right.$

Torque balance equation is written as

$T_{e}-T_{1}-\left(\frac{2}{p}\right) \beta \omega_{y}=\left(\frac{2}{p}\right) J \rho \omega_{y}$

The output voltage equations of 3-level SVPWM inverter are

$V_{q s \text { inv }}=\cos \delta V_{\alpha}+\sin \delta V_{\beta}$

$V_{d s i n v}=\sin \delta V_{\alpha}-\cos \delta V_{\beta}$

Where

$\begin{aligned} V_{\mathrm{a}} & =\frac{2}{a} V_{\mathrm{an}}-\frac{V_{\mathrm{bn}}}{\mathrm{a}}-\frac{\mathrm{V}_{\mathrm{cn}}}{\mathrm{a}} \\ V_{\mathrm{b}} & =0.577\left(\mathrm{~V}_{\mathrm{an}}-\mathrm{V}_{\mathrm{bn}}\right)\end{aligned}$ 


\section{CONTROL SYSTEM DESIGN}

It has been observed that the mathematical modelling of PM synchronous machine drive is non-linear because all the system equations are functions of $\omega_{\mathrm{r}}$. Thus, a conventional approach of linear system is not applicable to this non-linear model for designing control system. FLT has been used to change a non-linear model into a time invariant linear state model for designing control system for SV modulated voltage source inverter fed A.C drive system [4]. The proposed control technique is described in two-loop structure as revealed in fig.1. Proportional and an integral (PI) controller is designed as the outer loop for controlling speed and the inner loop is the current control loop for SVPWM 3-level inverter fed PMSM drive. The PI controller brings out a reference torque for the inner current loop. Developed electrical torque is a nonlinear function in terms of several quantities. A given developed electrical torque may be computed by choosing suitable values of torque angle and internal angle $(\psi)$. A non-linear controller is designed for the system to completely cancel the system nonlinearity. And thereafter linear (SFC) state feedback control law is used to improve the dynamic improvement of 3-level SV pulse width modulated inverter fed PM synchronous motor drive.

\section{A. PI Controller Design}

The outer loop was implemented for the speed controller loop. A (PI) proportional and an integral controller is used for this outer loop. The output of the speed loop is $T_{e}^{*}$ (reference electrical torque). By using reference torque, reference $\mathrm{d}-\mathrm{q}$ axis currents for the stator are generated. Encoder gives the values of rotor position and rotor speed.

A Proportional and an integral controller output equation is $T_{e}^{*}=K_{p} e+K_{i} \int_{0}^{t} e d t$

Error (e) is the difference between set speed and rotor speed. $\mathrm{e}=\omega_{\mathrm{e}}-\omega_{r}$

By substituting $\mathrm{P}=4$ in Eq. (26), torque balance equation is written as

$T_{e}-T_{l}-\left(\frac{1}{2}\right) \beta \omega_{r}=\left(\frac{1}{2}\right) J \rho \omega_{r}$

Eq. (32) \& (33) are substituting in Eq. (31) and then take the Laplace transform of these equations, we can get proportional gain $\left(K_{p}\right)$ and an integral gain $\left(K_{i}\right)$ of the controller.

$\frac{\omega_{\mathrm{f}}}{\omega_{\mathrm{e}}}=\frac{\mathrm{s}\left(\frac{2}{\mathrm{~J}} \mathrm{~K}_{\mathrm{p}}+1\right)+\frac{2}{\mathrm{~J}} \mathrm{~K}_{\mathrm{i}}}{\mathrm{s}^{2}+\mathrm{s}\left(\frac{\mathrm{B}}{\mathrm{J}}+\frac{2}{\mathrm{~J}} \mathrm{~K}_{\mathrm{p}}\right)+\frac{2}{\mathrm{~J}} \mathrm{~K}_{\mathrm{i}}}$

Eq. (34) is a Second order system transfer function. From the denominator, gains of the PI controller were found.

$\omega_{\mathrm{n}}^{2}=\frac{2}{\mathrm{I}} \mathrm{K}_{\mathrm{i}}$

(37)

$K_{i}=\omega_{n}^{2} \frac{I}{2}$

(38)

$2 \zeta \omega_{n}=\frac{\beta}{J}+\frac{2}{J} K_{p}$

(39)

$\left(2 \zeta \omega_{n}-\frac{\beta}{I}\right) \frac{I}{2}=K_{p}$

\section{B. Determination of d-q axis Reference Currents by Taking $\delta$ as Specification}

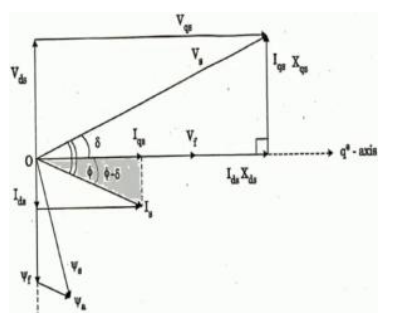

Fig.5. Phasor diagram of PMSM

The developed electrical torque is a function of PM stator field and rotor currents of the PM Synchronous machine. The developed electrical torque is non-linear function. For generating same torque, there are various possible values of currents were exists. D-q axis reference currents are generated by considering a change of load torque angle $(\delta)$ for 3-level SVPWM inverter fed PM Synchronous motor drive. Referring to the Phasor diagram in fig.5,

$$
\begin{aligned}
& =\frac{-V_{d s}}{V_{q S}^{I}}=\frac{V_{d \sin } v}{V_{q s} \sin v} \\
& \frac{-\mathrm{r}_{\mathrm{a}} \mathrm{i}_{\mathrm{ds}}+\omega_{\mathrm{r}} \mathrm{l}_{\mathrm{qs}} \mathrm{i}_{\mathrm{qs}}}{\mathrm{r}_{\mathrm{a}} \mathrm{i}_{\mathrm{qs}}+\omega_{\mathrm{r}} \mathrm{l}_{\mathrm{ds}} \mathrm{i}_{\mathrm{ds}}}=\frac{-\sin \delta \mathrm{V}_{\alpha}+\cos \delta \mathrm{V}_{\beta}}{-\cos \delta V_{\alpha}-\sin \delta V_{\beta}} \\
& \frac{-\mathrm{r}_{\mathrm{a}} 1_{\mathrm{ds}}+\omega_{\mathrm{r}} \mathrm{I}_{\mathrm{qs}} \mathrm{i}_{\mathrm{q} s}}{\mathrm{r}_{\mathrm{a}} \mathrm{i}_{\mathrm{q} s}+\omega_{\mathrm{r}} \mathrm{l}_{\mathrm{ds}} \mathrm{i}_{\mathrm{ds}}}=\frac{-V_{\mathrm{a}} \tan \delta}{}=\frac{\mathrm{V}_{\beta}}{-V_{\alpha}-V_{\beta} \tan \delta}
\end{aligned}
$$

By cross multiplying the above equation, we can get $\tan \delta$

$$
\tan \delta=\frac{i_{d s}\left(\left(-\mathrm{v}_{\alpha} \mathrm{r}_{\mathrm{a}}+\mathrm{v}_{\beta} \omega_{\mathrm{r}} \mathrm{l}_{\mathrm{ds}}\right)\right)+i_{\mathrm{qs}}\left(\left(\mathrm{v}_{\beta} \mathrm{r}_{\mathrm{a}}+\mathrm{v}_{\alpha} \omega_{\mathrm{r}} \mathrm{l}_{\mathrm{qs}}\right)\right)}{i_{d s}\left(\mathrm{v}_{\mathrm{\alpha}} \omega_{\mathrm{r}} \mathrm{l}_{\mathrm{ds}}+\mathrm{v}_{\beta} \mathrm{r}_{\mathrm{a}}\right)+i_{\mathrm{q} s}\left(\left(\mathrm{v}_{\mathrm{\alpha}} \mathrm{r}_{\mathrm{a}}-\mathrm{v}_{\beta} \omega_{\mathrm{r}} \mathrm{l}_{\mathrm{qs}}\right)\right)}
$$

From Eq. (39), $i_{d s}^{*}$ can be obtained as

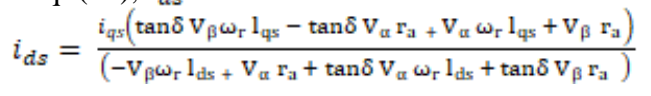

Developed electrical torque expression from Eq. (27) for a number of poles $(\mathrm{P})=4$ is

$$
\begin{aligned}
& T_{e}=3 \mathrm{i}_{\mathrm{q} s}\left(\left(l_{a d}-l_{a q}\right) i_{d s}+\psi\right)
\end{aligned}
$$

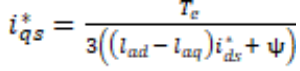

$$
\begin{aligned}
& \text { Substitute } i_{q s} \text { in Eq. (35) to get } i_{d s}^{*} \\
& i_{d s}^{*}=\frac{-b \pm \sqrt{b^{2}-4 a c}}{2 a} \\
& \text { Where } \mathrm{a}=3\left(\mathrm{l}_{\mathrm{ad}}-\mathrm{l}_{\mathrm{aq}}\right) \\
& \mathrm{b}=3 \psi
\end{aligned}
$$

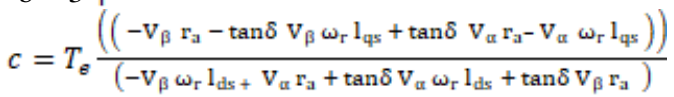

The value of $i_{q s}^{*}$ is obtained by substituting Eq. (43) in Eq. (44) as $i_{q s}^{*}=\frac{T_{a s}}{3\left(\left(\left(l_{a x d}-l_{a q}\right)\right)\left(\left(\frac{-b \pm \sqrt{b^{2}-4 \pi x}}{2 a}\right)\right)+(\psi)\right)}$

\section{Feedback Linearization Technique}

State space model using voltage equations are

$x^{x}=\left(A^{\prime}+\omega_{r} A^{\prime \prime}\right) x+B u$

$\mathrm{u}=\left(\omega_{r}-\omega_{d 1}\right) K_{1} x+u_{2}$

Where $A^{x}$ is the linear matrix and $A^{n}$ is the non linear matrix, it is required to go for cancellation of this term. We consider the feedback control law form

$u_{1}+u_{2}=u$

Where $u_{1} \& u_{2}$ are input control vector of nonlinear part and linear part.

$$
u_{1}=\omega_{r} K_{1} x
$$


$\mathrm{x}^{\mathrm{x}}=\left(\mathrm{A}^{\prime} \mathrm{x}+\omega_{\mathrm{r}}\left(\mathrm{A}^{\prime \prime}+\mathrm{BK}_{1}\right) \mathrm{x}+\mathrm{B} \mathrm{u_{2 }}\right.$

From the Eq. (48) $\left(A^{n t}+B K_{1}\right)$ term, becomes zero for the exact cancellation of nonlinear term [10].

$\mathrm{A}^{n}=-\mathrm{BK}_{1}$

Thus, system nonlinearity is exactly cancelled by substituting Eq. (49), Eq. (52) in Eq. (48).

\section{RESULTS AND DISCUSSIONS}
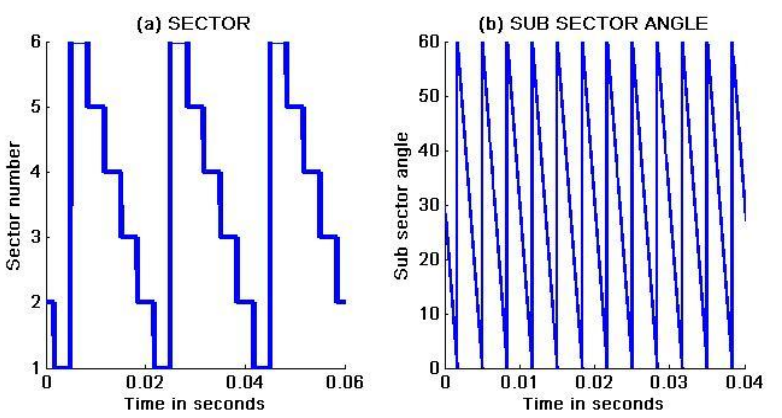

Fig.6. Simulation waveform of sector and sub-sector angle
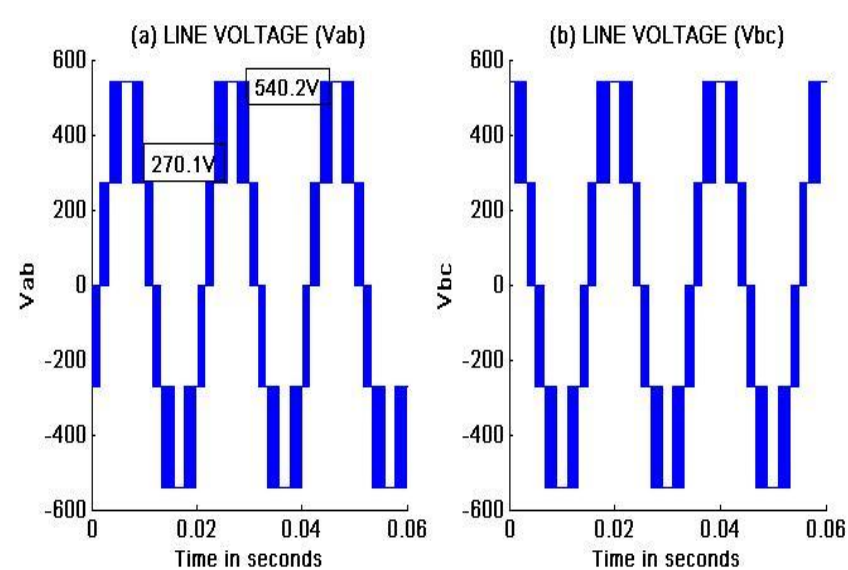

Fig.7. Simulation results of 3-level SV pulse width modulated inverter output line voltages
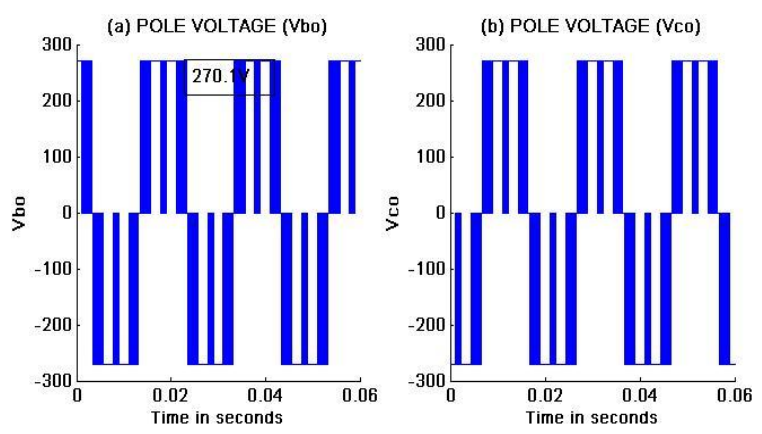

Fig.8. Simulation results of the 3-level SV pulse width

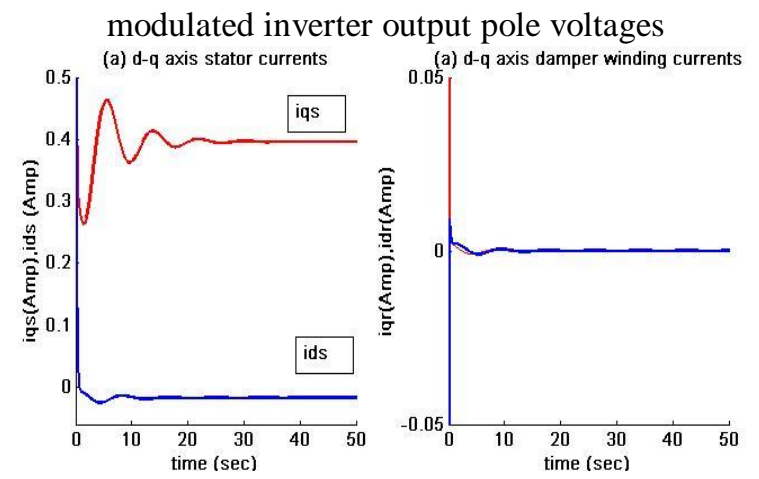

Fig.9. Simulation results of 3-level SVPWM fed PMSM drive $d-q$ axis stator and damper winding currents corresponding to a frequency of $40 \mathrm{~Hz}$

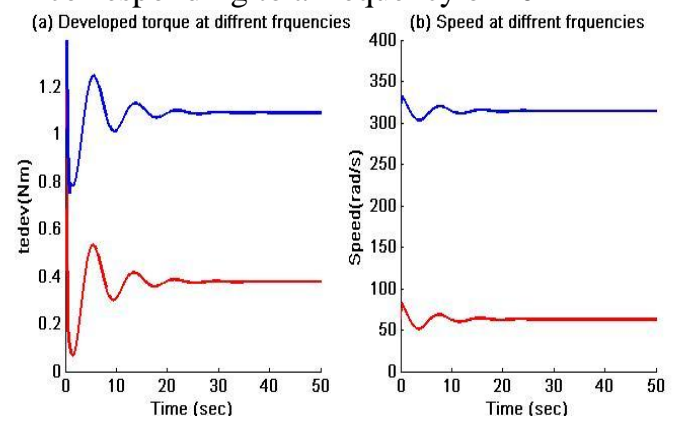

Fig.10. Simulation results of 3-level SV pulse width modulated inverter fed PMSM drive (a) for developed torque at a $10 \mathrm{~Hz}$ (red) and at a $50 \mathrm{~Hz}$ (blue) frequency (b) for speed at different frequencies of $10 \mathrm{~Hz}$ (red) and $50 \mathrm{~Hz}$ (blue) at a constant load torque $0.2 \mathrm{Nm}$.
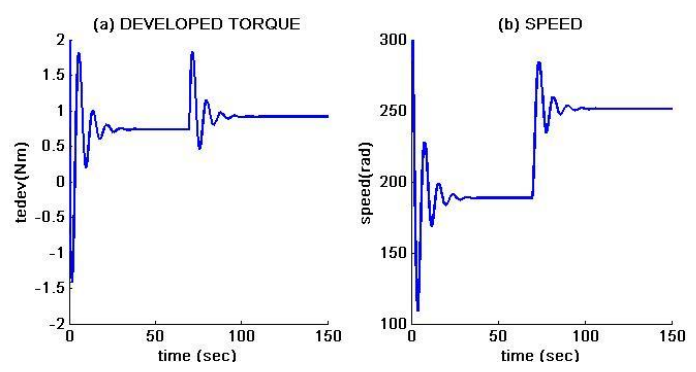

Fig.11. Simulation results of 3-level SV pulse width modulated inverter fed PMSM drive (a) for a change in developed electrical torque at different frequencies of $30 \mathrm{~Hz}$ to $40 \mathrm{~Hz}$ with $0.2 \mathrm{Nm}$ load torque. (b) At a step increment in speed at different frequencies of $30 \mathrm{~Hz}$ to $40 \mathrm{~Hz}$ with $0.2 \mathrm{Nm}$ load torque
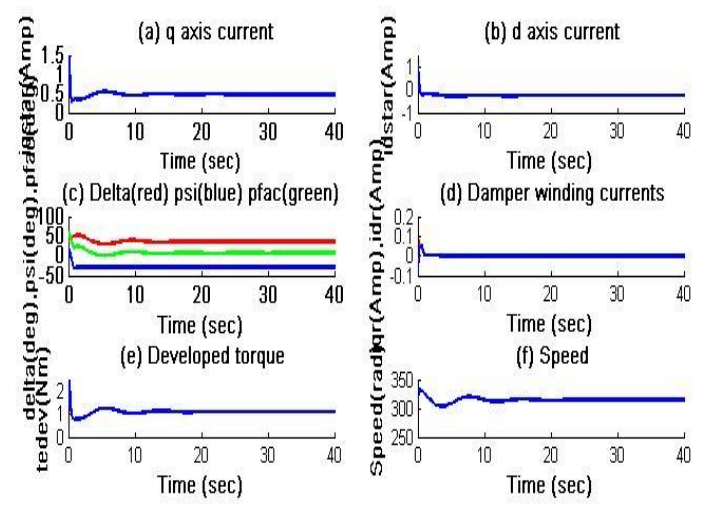

Fig.12. Simulation results of closed loop control of SVPWM 3-level inverter fed PMSM drive at a torque angle $\delta=10^{\circ}$ at a constant frequency of $50 \mathrm{~Hz}$ 

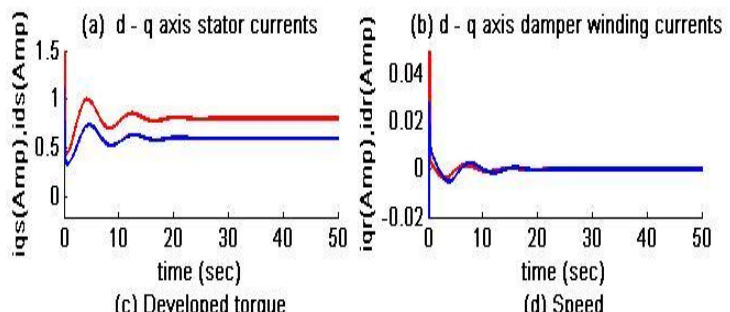

(c) Developed torque
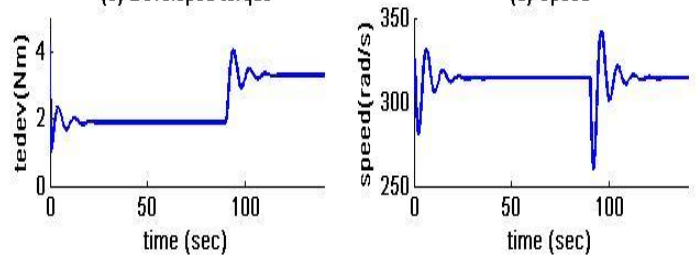

Fig.13. Simulation results of 3-level SV pulse width modulated inverter fed PMSM drive at a step increment in torque from $1 \mathrm{Nm}$ to $2.4 \mathrm{Nm}$ corresponding to a frequency of $50 \mathrm{~Hz}$

Fig.6 (a) shows the simulation waveform of the sectors and the recognition of reference voltage vector in all sector divisions based on the space vector angle and fig.6 (b) shows the sub-sector angle calculation in particular sector and its region.

Fig.7 (a) and (b) shows the 3-level SV pulse width modulated inverter output line voltage waveforms of $\mathrm{V}_{\mathrm{ab}}$ \& $\mathrm{V}_{\mathrm{bc}}$ with the different 3 levels are $0, \frac{V_{d c}}{2}$ (270.1 volts), $V_{d c}$ (540.2 volts) during positive half cycle.

The output pole voltages of $\mathrm{V}_{\mathrm{bo}}$ and $\mathrm{V}_{\text {co }}$ of 3 level SV pulse width modulated inverter waveforms are shown in Fig.8 (a) $\&$ (b) with the different 3 levels are $\frac{V_{d c}}{2}(270.1$ volts $), 0$, $\frac{-V_{d c}}{2}$ (-270.1 volts).

At constant load torque with a frequency of $40 \mathrm{~Hz}$ the damper winding and stator $\mathrm{d}-\mathrm{q}$ currents in rotating reference frame was shown in Fig.9 (a) and (b). I observed that the damper winding currents in its steady state are found to be is zero. At a constant load torque with load angle $\delta=40^{\circ}$, the response of developed torque for closed loop control of 3-phase 3-level SVPWM inverter fed PMSM drive for different speeds at frequencies of $10 \mathrm{~Hz}$ (red) and $50 \mathrm{~Hz}$ (blue) is observed in fig.10(a). In fig.10 (b), response of speed for closed loop control of a 3-level inverter driven PMSM drive employing SVPWM at different frequencies of $10 \mathrm{~Hz}$ (red) \& $50 \mathrm{~Hz}$ (blue) is observed.

Fig. 11 (a) shows the change in developed torque at $0.188 \mathrm{Nm}$ to $0.692 \mathrm{Nm}$ at 22.4 seconds corresponding to a frequency of $30 \mathrm{~Hz}$ and also the change in developed torque is observed at $0.44 \mathrm{Nm}$ to $0.92 \mathrm{Nm}$ at 95.8 seconds corresponding to a $40 \mathrm{~Hz}$ frequency at a constant load torque. Fig.11(b) shows the step increment in speed at $155.9 \mathrm{Nm}$ to $188.8 \mathrm{Nm}$ at 25.8 seconds corresponding to a $20 \mathrm{~Hz}$ frequency and also step increment in speed at $191.1 \mathrm{Nm}$ to $251 \mathrm{Nm}$ at 96 seconds corresponding to a $40 \mathrm{~Hz}$ frequency at a constant load torque of $0.2 \mathrm{Nm}$.

At a constant load torque with load angle $\delta=10^{\circ}$, simulation results for closed loop control of SVPWM 3-level inverter driven PMSM drive was observed in Fig. 12 at a constant frequency of $50 \mathrm{~Hz}$.
Fig.13 shows simulation results of closed loop control of 3-level SVPWM voltage source inverter driven PMSM drive at a step increment in torque from $1 \mathrm{Nm}$ to $2.4 \mathrm{Nm}$ at constant frequency of $50 \mathrm{~Hz}$. The response of d-q axis stator and damper currents, developed torque and speed is observed in these results and were found to be settling down at a finite value under steady state conditions.

\section{CONCLUSION}

A novel circuit analysis realization of the 3-phase 3-level SVPWM strategy was developed. There exist a closely relationship between on time period computation and arrangement for a sequence of switches due to symmetry of six sectors. Hence it can complete the analysis of computation of the three-level inverter in particular triangular sectors and then mapping the on time periods in another sector through the relationships between them. Triggering pulses was generated using this SVPWM strategy and these are applied to 3-level inverter driven by PMSM drive. In this work, closed loop control scheme of 3-level diode point clamped inverter driven by PMSM practicing applications of SVPWM control strategy has been implemented. Linear system theory techniques are not applicable to the control system design, so alternative techniques have been proposed. Control system design has been worked out by using the conventional two-loop structure. Proportional and an integral (PI) controller are designed as the outer loop for a PMSM drive to improve the dynamics of the system. A nonlinear controller using FLT (feedback linearization technique) has been designed to control the inner loop. From the observation of simulation results, we can conclude that a response of torque and speed of PMSM drive has been improved using 3-level SVPWM inverter. Also from observations, we can conclude that drive dynamic performance was greatly improved by using robust control system design techniques.

\section{REFERENCES}

1. Ayse Kocalmis \& Sedat Sunter, "Simulation of a Space Vector PWM Controller for a Three-Level Voltage-Fed Inverter Motor Drive”, 32nd annual conference on IEEE Industrial Electronics, 6-10 Nov 2006.

2. Haibing $\mathrm{Hu}$, Wenxi Yao, and Zhengyu Lu, "Design and Implementation of Three-Level Space Vector PWM IP Core for FPGAs" vol.22, Issue.6, November 2007, IEEE transactions on power electronics.

3. Ashwin M. Khambadkone and Amitkumar Gupta, " A Space vector PWM Scheme for Multilevel Inverters Based on Two level Space Vector PWM", vol.53,Issue.5,October 2006 IEEE transactions on industrial electronics.

4. P.Ramana, K. Alice mary, M.S Kalavathi "State Feedback Linearization of a Non-linear Permanent Magnet Synchronous Motor Drive", Indonesian Journal of Electrical Engineering and Computer Science,vol.1, pp. 1-6, 2016.

5. P. Ramana, K. Alice Mary and M. Surya Kalavathi “Design Methodology for Torque angle Control of a Nonlinear Vector Controlled Permanent Magnet Synchronous Motor", world journal of Modelling Simulation (WJMS), vol.12, Nov-2016, pp-281-291.

6. Wanchai Subsingha, "Design and Analysis Three Phase Three Level Diode-Clamped Grid Connected Inverter" Published by Elsevier, vol.89, June 2016, pages 130-136.

7. Prasanta sarkar, Sourav bhunia, "SVPWM based vector control of PMSM drive in delta domain", International Conference on Electrical, Computer and Communication Engineering (ECCE), February 16-18, 2017, Cox’s Bazar, Bangladesh. 


\section{Design and Analysis of closed loop control of Multilevel SVPWM Inverter fed PMSM Drive}

8. R.G.Shriwastava, M.B. Daigavane, P. M. Daigavane, "Simulation Analysis of Three Level Diode Clamped Multilevel Inverter Fed PMSM Drive Using Carrier Based Space Vector Pulse Width Modulation (CB-SVPWM)", Published by Elsevier, 7th International Conference on Communication, Computing and Virtualization 2016.

9. Dr.Promod Agarwal \& Dr.M.K.Pathak, "Comparison of SPWM Multilevel Inverter fed PMSM drive with two level Inverter Fed Drive", IEEE International conference on Recent Advances and Innovations in Engineering (ICRAIE-2014), May 09-11, 2014.

10. K.S.Low, M.F. Rahman and K.W. Lim. "The d-q transformation and feedback linearization of permanent magnet synchronous motor".IEEE Catalogue No-95TH-8025, pp-292-296, 1995.

\section{AUTHORS PROFILE}

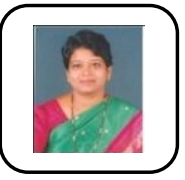

Dr. Karlapudy Alice Mary is currently working as a Professor in EEE Dept. GEC, Gudlavalleru, Krishna district, A.P. She received BE degree in Electrical Power Engineering from Govt. B.D.T College of Engineering \& Technology Davanagere, Karnataka, India, ME in Power Electronics and Drives from IITR, Roorkee U.P. India and Ph.D from IIT, KGP, W.B. India. She has 37 years of teaching experience, worked at different levels as Director of outreach program and Principal of three various engineering institutions and published around 75 papers. She is a recipient of 16 awards for her life time achievement in E\&E engineering field. Her research interests include Control System Applications to Power Electronics and Machine Drives and produced 3 Ph.Ds.

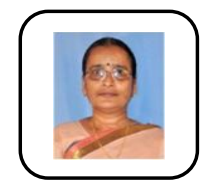

Dr. G.Saraswati is currently working as a Professor\& Vice-Principal (Academics) in EEE Dept., JNTUV, and Vijayanagaram, India. She received BE degree in Electrical Engineering from Andhra University, Visakhapatnam, India, ME in Control systems from Andhra University, Visakhapatnam and Ph.D from J.N.T.University, Hyderabad. She has 30 years of teaching experience, worked at different levels and published around 35 papers. Her research interests include order reduction of large scale systems, Renewable energy sources and micro grids and controlling of multi area and distributed systems.

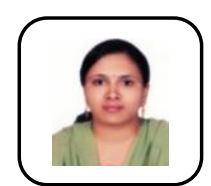

Mrs. K. Lavanya is working as an assistant Professor in the Department of Electrical and Electronics Engineering at ANITS, Sangivalasa, Bheemili mandal, Visakhapatnam, A.P. India. She received BE degree in Electrical and Electronics Engineering from TPIST, bobbili mandal, India, M.Tech in Power Electronics from JNTU Hyderabad, Aurora Engineering College, A.P, India and pursuing Ph.D in JNTUK, Kakinada. She has 13 years of teaching experience. Her research area includes Control System applications to Power Electronics and Machine Drives. 